Khan, M. R., Darwaish, AMN and Tahir U.

\title{
Sodium, Potassium, Iron, Calcium and Phosphorus Content of Some Pakistani Condiments
}

\author{
Khan, M. R. ${ }^{* 1}$, Darwaish, $\mathrm{AMN}^{2}$ and Tahir $\mathrm{U}^{3}{ }^{3}$ \\ *1,2Department of Environmental Science and Policy, Lahore School of \\ Economics Lahore, Pakistan, \\ ${ }^{2}$ Department of Chemistry, Government College of Science, Lahore Pakistan \\ *drrafiq@lahoreschool.edu.pk
}

\begin{abstract}
Macro-inorganic elements such as sodium, potassium, iron calcium and phosphorus were determined in condiments popularly used for preparation of routine meals in Pakistan by applying techniques like flame photometry, spectrophotometry and volumetric analysis. The largest amount of sodium and potassium was found to be present in medicago, while cinnamin leaves exhibited the smallest amount. Black pepper was found rich in iron and medicago was found rich in calcium. High phosphorus content was exhibited by parsley.
\end{abstract}

Keywords: sodium, potassium, iron, calcium, phosphorus, condiments, Pakistan

\section{Introduction}

Minerals, such as sodium, potassium, iron calcium and phosphorus play a vital role in the construction and functioning of the living body. These are usually supplied to the body from exogenous sources, mostly through raw and cooked foodstuffs. Their importance has been highlighted in both old and recent books that have appeared in literature [1-2]. On the basis of their nutritive value, these have been under intensive investigation all over the world, particularly with reference to their demand and supply. The trends in prevalence and magnitude of vitamin and mineral supplement usage and their correlation with health have been reported by Bender et al. [3].

Some work, in the said context, has also been carried out in Pakistan from the point of view of animal and human nutrition. A large number of raw and cooked foodstuffs have been analyzed for their mineral contents [4], [5] and [6]. Following the same track, the purpose of the work undertaken here was to determine the presence of sodium, potassium, iron, calcium and phosphorus in the condiments commonly used in Pakistan and subsequent value of the nutritional status of these condiments, whether they meet the requirements of the people of Pakistan. 
Sodium, Potassium, Iron, Calcium and Phosphorus Content of Some Pakistani Condiments

\subsection{Samples}

\section{Materials and Methods}

The samples of the condiments were selected on the basis of the review of literature. Only those were selected on which no work or little work was reported in literature. As all the samples were easily available in Lahore, they were collected from the local market without any difficulty. Only fresh and healthy condiments were obtained. Most of the condiments were processed while they were fresh. However, the samples were preserved over prolonged periods in dry sample bottles.

\subsection{Determination of Moisture}

Moisture was determined by Oven Drying Method [7]. 10g of the condiment sample was taken in a pre-weighed china dish. It was then dried to a constant weight at $105^{\circ} \mathrm{C}$ in an oven by repeating heating and weighing at intervals of one hour. The dish with the material was finally weighed after cooling and the loss in weight was reported as percentage of moisture.

\subsection{Determination of Ash}

Ash was determined by igniting the oven-dried material from a $10 \mathrm{~g}$ sample in a Muffle Furnace and reporting the weight of ash as percentage of the starting sample [7]. The sample was placed in a muffle furnace and ignited at $550^{\circ} \mathrm{C}$ for 4 to 5 hours till the ash was nearly white. Then $1-2 \mathrm{ml}$ concentrated $\mathrm{HNO}_{3}$ was added and the dish was again placed in the furnace to render it carbon free. The china dish was removed from the furnace, cooled in a desiccator and weighed. The process was repeated to a constant weight. The ash was reported as the percentage of sample taken before drying and igniting.

\subsection{Digestion of Sample}

To the ash left in the crucible was added $3 \mathrm{ml}$ concentrated $\mathrm{HCl}$. The contents were heated at $105^{\circ} \mathrm{C}$ to dryness. The residue was dissolved in deionized water and filtered through Whatman No 42 into a $50 \mathrm{ml}$ volumetric flask. The residue on the filter paper was washed with deionized water and washings were also transferred to the volumetric flask. The volume was made up to the mark with deionized distilled water. The solution thus prepared was ready for the determination of all macro-elements.

\subsection{Determination of Sodium and Potassium}

Sodium and potassium were determined by Flame Photometry [8]. To do so, the samples and standards were injected and read in JASCO-AID-3 Flame Photometer equipped with the auto-dilution facility and subsequently compared.

The instructions given in the operational manual were strictly followed to prepare the standards and to read the samples.

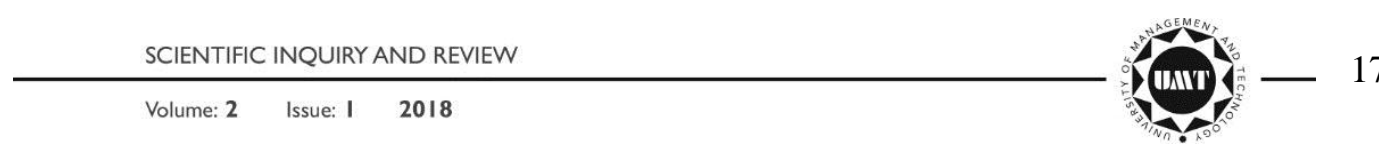


Khan, M. R., Darwaish, AMN and Tahir U.

\subsection{Determination of Iron}

Iron was determined by Spectrophotometric Method [8]. Iron in the ferric state forms an intense color with potassium thiocyanate that can be measured even if iron is present in a very small amount. The iron was in the ferric state in the samples prepared above. Colors were developed treating sample solutions and stock standards of iron adequately diluted with I\% potassium thiocyanate solution and subsequently read in "Chamtrix Type 24 Digital Colorimeter." and compared. The optical densities were converted to milligrams of iron using a standard curve prepared from readings of colors developed from different concentrations of iron derived from standard iron solution obtained by dissolving iron wire in $\mathrm{HCl}$ and the subsequent oxidation of the dissolved ferrous ions to ferric state with nitric acid.

\subsection{Determination of Calcium}

Calcium was determined by Volumetric Method using Substitution Titration [8]. To do so, an adequate volume of the sample solution was titrated against a standard solution of EDTA using Solochrome Black (Eriochrome Black T) indicator. To 25 $\mathrm{ml}$ of the sample solution was added $25 \mathrm{ml}$ distilled water in a conical flask and then were added $2 \mathrm{ml}$ ammonia-ammonium chloride buffer $\mathrm{pH} 10.0,1.0 \mathrm{ml}$ of $0.2 \mathrm{M}$ Mg- EDTA and 1 to 2 drops of Solochrome Black (Eriochrome Black). The solution was titrated against standard EDTA solution, till the color changed from wine red to clear blue. The concentration of calcium was calculated from the relationship:

1 mole of EDTA = 1 mole of $\mathrm{Ca}$

\subsection{Determination of Phosphorus}

Phosphorus was determined by Molybdenum Blue Method [8]. Based on the principle that the orthophosphate and the molybdate ions condense in an acidic solution to give phosphomolybdic acid, which on selective reduction with hydrazinumsulphate produces a blue color that is read for absorbance in a spectrophotometer. To carry out the determination, $25 \mathrm{ml}$ of the sample prepared as above and stored in a $50 \mathrm{ml}$ volumetric flask, was added with $5 \mathrm{ml}$ molybdate solution and $2 \mathrm{ml}$ hydrazinumsulphate solution. The mixture was diluted to the mark with deionized distilled water. The contents were mixed well and the flask was kept immersed in a boiling water bath for 10 minutes. The flask was then removed and cooled rapidly and shaken. The volume was adjusted and the absorbance was read in a "Chamtrix Type 24 Digital Colorimeter" against the blank at $830 \mathrm{~nm}$. The optical densities were converted to phosphorus concentrations by comparison with a standard curve prepared using a standard phosphate solution. 
Sodium, Potassium, Iron, Calcium and Phosphorus Content of Some Pakistani Condiments

Table 1: Percentage of Moisture and Ash in the condiments

\begin{tabular}{ccccc}
\hline $\begin{array}{c}\text { Ser. } \\
\text { No. }\end{array}$ & $\begin{array}{c}\text { English Name / Local } \\
\text { Name }\end{array}$ & Botanical Name & $\begin{array}{c}\text { Moisture } \\
\text { g/100g }\end{array}$ & $\begin{array}{c}\text { Ash } \\
\text { g/100g }\end{array}$ \\
\hline 1 & Cinnamon/Darchini & Cinnamomumverum & 1.25 & 2.30 \\
2 & Cinnamon/ Taze Pat & Cinnamomumverum & 10.30 & 3.80 \\
3 & Mace/ Javatri (Seeds) & Myristica fragrance & 10.10 & 1.00 \\
4 & Nutmeg/ Jaiphul & Carumcarvi & 7.70 & 4.40 \\
5 & Cardamom/MotiAlaichi & Amomum false & 9.30 & 4.60 \\
6 & Caraway/Kala Zeera & Carvumcarvi & 9.80 & 6.30 \\
7 & Cumin/ SufaidZeera & Cuminumcyminium & 10.10 & 6.00 \\
8 & Black Pepper/Kali Mirch & Piper nigrum & 6.90 & 0.80 \\
9 & White Pepper/Sufaid Mir & Piper nigrum & 6.90 & 1.30 \\
10 & Clove/Loung & Eugenia cryaphyllus & 8.00 & 3.80 \\
11 & Red Chillies/LalMirch & Capsicum frutescens & 25.60 & 4.40 \\
12 & Turmeric/Haldi & Curcuma longa & 3.80 & 4.20 \\
13 & Coriander/ Dhania & Corianderumsativum & 10.50 & 7.00 \\
14 & Ginger (Powder)/Adrak & Zingibarofficinale & 4.50 & 3.70 \\
15 & Maticago (Seeds)/Methi & Trigonellafoenumgraceum & 24.30 & 14.60 \\
16 & Fennel/Saunf & Foeniculumvalgare & 7.30 & 8.90 \\
17 & Parsley/ Ajwain & Carumcopticum & 6.50 & 9.80 \\
18 & Wild Melon/Kuchri & Curcuma zedoriarosc & 9.80 & 2.90 \\
19 & Malthree & Malthree & 8.90 & 3.20 \\
20 & Onion (Seeds)/ Piazi & Allium sepa & 6.80 & 5.00 \\
\hline
\end{tabular}

Table 2: Trace metal contents of different spices and condiments

\begin{tabular}{llllllll}
\hline S.N. & English Name & Botanical Name & Na & K & Fe & Ca & $P$
\end{tabular}

\begin{tabular}{cccccccc}
\hline 1 & & \multicolumn{5}{c}{$(\mathbf{m g} / \mathbf{1 0 0 g})$} \\
2 & Cinnamon/Darchini & Cinnamomumverum & 46.00 & 82.60 & Nil & 620 & 1.50 \\
3 & Mace/ Javatri (Seeds) & Myristica fragrance & 92.00 & 40.80 & Nil & 40 & 3.83 \\
4 & Nutmeg/Jaiphul & Carumcarvi & 92.00 & 241.8 & 0.20 & 40 & 7.50 \\
5 & Cardamom/MotiAlaic & Amomum false & 460.00 & 1007. & Nil & 200 & 12.9 \\
6 & Caraway/Kala Zeera & Carvumcarvi & 368.00304 .2 & 0.52 & 380 & 50.0 \\
7 & Cumin/SufaidZeera & Cuminumcyminium & 322.00 & 405.6 & Nil & 500 & 9.93
\end{tabular}

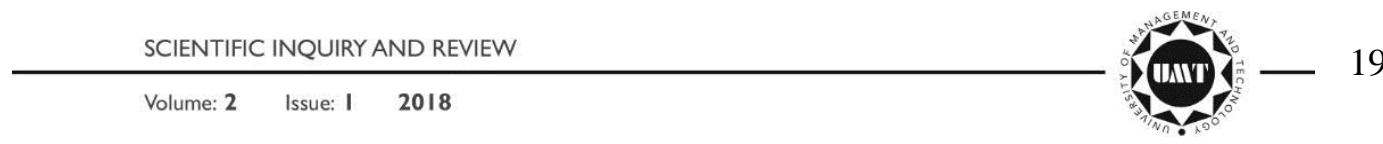


Khan, M. R., Darwaish, AMN and Tahir U.

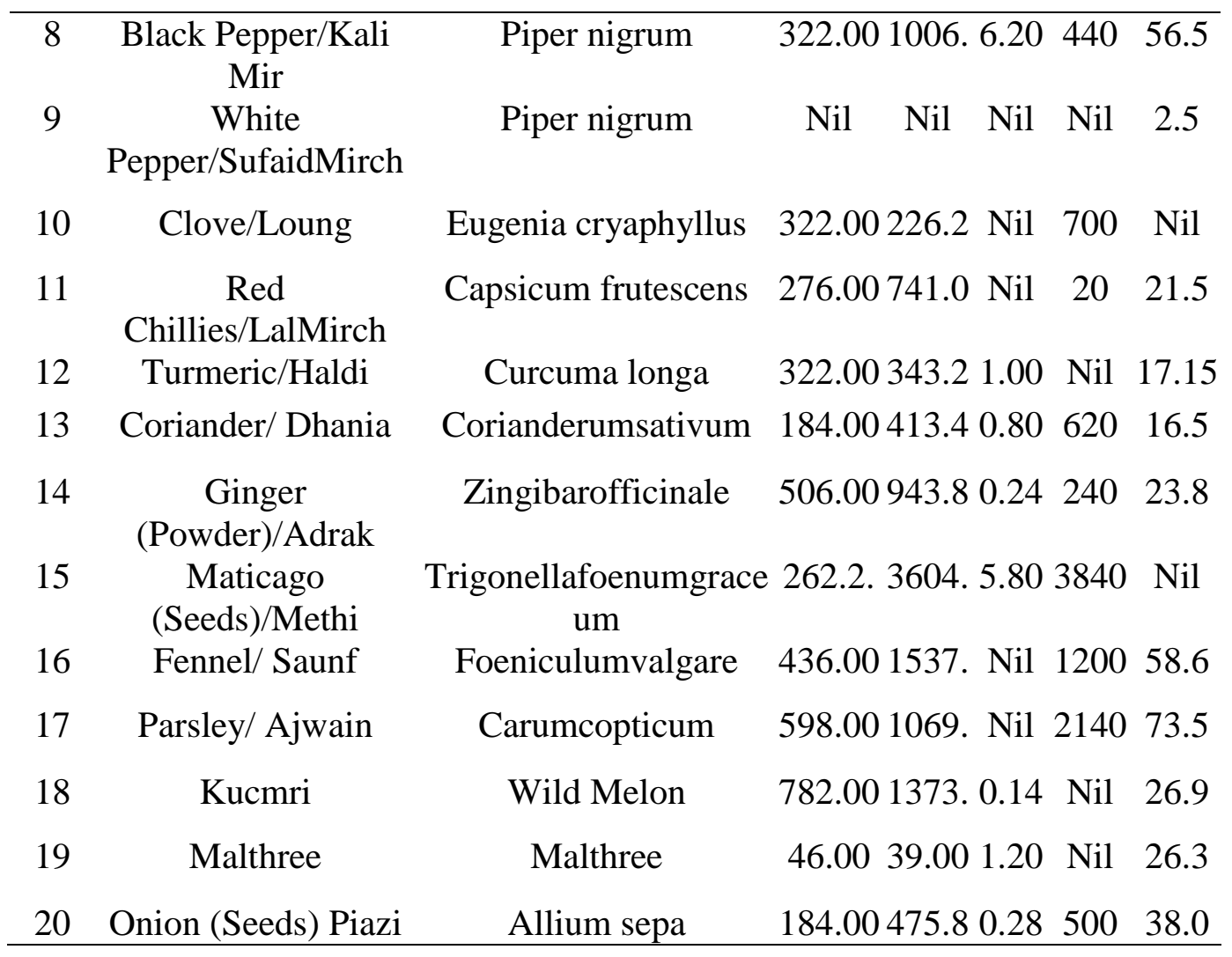

\section{Results and Discussion}

The percentages of moisture and ash in the samples under investigation are reported in table 1, while $\mathrm{Na}, \mathrm{K}, \mathrm{Fe}, \mathrm{Ca}$ and $\mathrm{P}$ contents of different samples are reported in table 2 .

Table 1 indicates that the moisture content of most of the condiments is less than $10 \%$. Only a few such as red chilies and masticago exhibit moisture content more than $20 \%$. The least moisture content is exhibited by cinnamon and turmeric.

The ash consents of most of the condiments are in the range of 6\% to $9 \%$. Only one condiment that is masticago exhibits ash content $14.6 \%$. The least ash contents are exhibited by mace, black pepper and white pepper.

Table 2 indicates that the sodium present in different samples of the condiments lies in the range 46.0 to $782 \mathrm{~g} \%$. There is only one condiment that is masticago, which exhibits a larger amount of sodium [2622 $\mathrm{mg} \%$ ). The largest amount of potassium is exhibited by medicago, while white pepper contains no potassium and the same is true for cinnamon leaves. Other condiments contain potassium in the range 39 to $1537 \mathrm{mg} / 100 \mathrm{~g}$.

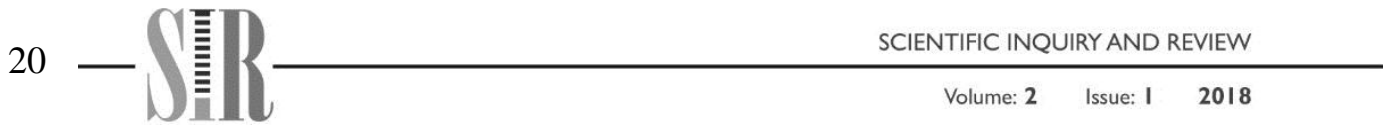


Sodium, Potassium, Iron, Calcium and Phosphorus Content of Some Pakistani Condiments

As indicated in table 2, the largest amount of iron is in black pepper. The condiments that contain almost no ion are cinnamon, mace, cardamom, cumin, white pepper, clove, red chilies, fennel and parsley. Most of the condiments contain iron in the range of 0.2 to $1.2 \mathrm{mg}$ per $100 \mathrm{~g}$.

The comparison reveals that medicago contains the highest amount of calcium. It is followed by parsley, fennel and cinnamon leaves. A few that contain no calcium are white pepper, turmeric, wild melon and malthree.

\section{Conclusion}

From the discussion it was concluded that the largest amount of sodium and potassium was present in medicago, while cinnamin leaves exhibited their smallest amounts. Black pepper was found rich in iron and medicago was found rich in calcium. High phosphorus content was exhibited by parsley. The comparison revealed that medicago contained the highest amount of calcium. A few that contained no calcium were white pepper, turmeric, wild melon and malthree. The condiments that contained the largest amount of phosphorus were parsley, fennel, black pepper and caraway. The overall conclusion was that the condiments used in Pakistan are adequate source of the sodium, potassium, iron, calcium and phosphorus from nutritional point of view.

\section{References}

[1] Sherman CH, Sherman LC. Essentials of Nutrition. $2^{\text {nd }}$ ed. London: Macmillan and Comp; 1947.

[2] Khan, MR. Biochemistry. $2^{\text {nd }}$ ed. Lahore: The Caravan Book House; 1988.

[3] Bender MM, Levy AS, Schucker RE, Yetley EA. Trends in prevalence and magnitude of vitamin and mineral supplement usage and correlation with health status. J Am Diet Assoc. 1992;92(9):096-101.

[4] Chughtai MD, Khan AW. Nutritive Value of Foodstuffs and Planning of Satisfactory Diets in Pakistan. Part 1: Composition of Raw Foodstuffs.

Lahore: Department of Chemistry, University of the Punjab;1960.

[5] Hussain T. Food Composition Table for Pakistan. Islamabad: Government of Pakistan. Ministry of Planning and Development, Planning and Development Division; 1985.

[6] Chughtai MD, Khan MR, Akhtar J, Khanum H. Nutrutive Value of Foodstuffs - IX. Some Cooked Foods Prepared by Conventional Methods. Pak J Sci Res. 1979;21(3-4):266-78.

[7] Association of Official Agricultural Chemists (AOAC). Official methods of analysis. 12th ed. Washington, DC: AOAC; 1975. 64-65 p.

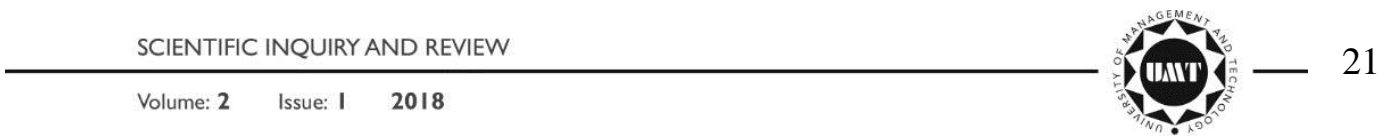


Khan, M. R., Darwaish, AMN and Tahir U.

[8] Bassett J, Denny RC, Jeffery GH, Mendham J. Vogel's Textbook of Quantitative Inorganic Analysis. 4th ed. London: The English Language Book Society and Longman; 1978. 